\title{
Percutaneous pedicle screw fixation combined with percutaneous vertebroplasty for the treatment of thoracic and lumbar metastatic tumor
}

\section{Xiaowei Ma}

Hebei Medical University Fourth Affiliated Hospital and Hebei Provincial Tumor Hospital

\section{Yi Zhao}

Hebei Medical University Fourth Affiliated Hospital and Hebei Provincial Tumor Hospital Jiazheng Zhao

Hebei Medical University Fourth Affiliated Hospital and Hebei Provincial Tumor Hospital Hongzeng Wu

Hebei Medical University Fourth Affiliated Hospital and Hebei Provincial Tumor Hospital

Helin Feng ( $\square$ helinfeng0311@163.com )

Hebei Medical University Fourth Affiliated Hospital and Hebei Provincial Tumor Hospital https://orcid.org/0000-0002-7260-5485

\section{Research Article}

Keywords: Percutaneous pedicle screw fixation, Percutaneous vertebroplasty, Bone metastases, Thoracic and lumbar disease, Spine

Posted Date: June 25th, 2021

DOl: https://doi.org/10.21203/rs.3.rs-624695/v1

License: (9) This work is licensed under a Creative Commons Attribution 4.0 International License. Read Full License 


\section{Abstract}

Background Evaluation of the clinical efficacy of percutaneous pedicle screw fixation (PPSF) combined with percutaneous vertebroplasty (PVP) in the treatment of thoracic and lumbar metastatic tumor.

Methods 20 patients with thoracic and lumbar metastatic tumor were treated with PPSF combined with PVP and followed up 6-25 months. Using the visual analog scale (VAS) and the Barthel Index of Activities of Daily Living (BIADL) to evaluate pain intensity and quality of life before surgery and at 7 days, 3 months, 6 months after treatment.

Results In this study, a total of 20 patients were followed up for 6-25 months (mean time was 14.10 months). The VAS scores of all patients were significantly decreased, while the BIADL scores were significantly increased. No patients suffered from complications such as infection, pedicle screw loosening or PMMA oozing. Spine stability was observed in all the surviving patients during the follow-up.

Conclusions PPSF combined with PVP is a potentially viable treatment for thoracolumbar metastases in patients with poor systemic condition or patients who refuse to undergo a conventional open procedure such as en bloc corpectomy, and in the presence of vertebral instability or pathological fracture without significant spinal compression.

\section{Background}

As the hardest organ in the body, bones play a vital role in locomotion and structural support, and the whole body is in a dynamic balance between bone synthesis and osteolysis, which makes bones a reservoir of minerals and energy[1]. Due to its particularity, bone has become the third most metastatic site of malignant tumors after lung and liver[2]. Bone metastasis can occur in many solid tumors, including carcinoma of thyroid, pulmonary neoplasm, breast cancer, colorectal cancer and melanoma, among which $70 \%$ of patients with prostate cancer and breast cancer can take place bone metastases[3]. In $25-30 \%$ of cancer sufferers, bone metastasis is the first manifestation of malignant tumor[4]. Unfortunately, once bone metastasis occurs, it is difficult to completely cure it and is associated with bone related events such as pain, hypercalcemia, compression of the spinal cord or cauda equina, spinal instability and pathological fractures, all of which can impair the patient's functional status, cause great pain to the patient, and seriously influence the living quality and survival[5].

In recent years, as we in cancer treatment has made significant progress[6], metastasis of cancer patients survival significantly extended, the incidence of spinal metastases also will increase[7], people begin to pay more attention to the best surgical treatment of spinal metastases, have turned their attention to improve the quality of life and reduce the length of hospital stay, and successfully introduced many minimally invasive techniques used to reduce the risk of surgery and postoperative complications[8]. Traditional open spinal surgery is characterized by great trauma, large amount of bleeding, high risk, slow recovery, and many complications after operation, which limits its clinical application and development[9]. PVP is a minimally invasive technique that uses a thin puncture needle to puncture 
through the skin and inject polymethylmethacrylate (PMMA) directly into the vertebral pedicle under the guidance of image technology, in order to stabilize and strengthen the vertebral body, ward off further subside of vertebral body, compression of spinal cord and relieve lower back pain[10]. Good clinical results have been achieved in the remedy of spinal metastases. PPSF can damage the back muscle as little as possible to avoid ischemic necrosis and denervation, which is conducive to the functional recovery of patients. PPSF combined with PVP is recommended for patients with spinal metastases who have poor systemic condition or who refuse to undergo a conventional open procedure such as an anterior approach or total en bloc spondylectomy, and where there is vertebral instability or pathological fracture without significant spinal compression. This method has been used in the therapy of spinal metastases and achieved good clinical results, but there are no literature reports two methods used in the treatment of advanced malignant tumor bone metastases. Therefore, this surgical approach, assess feasibility, the effectiveness and safety of minimally invasive surgery are described in this paper, which will provide a new idea for clinical treatment.

\section{Methods}

\section{Population Data}

This case series include a total of 20 patients with thoracic and lumbar metastatic tumor. The inclusion standard included: (1) pathological fractures of the thoracolumbar vertebral body caused by tumor bone metastasis confirmed by postoperative pathology, (2) no spinal cord and nerve injury confirmed by CT and MRI, no obvious spinal canal occupying, (3) The patient is generally in good condition and can tolerate surgery, however, there are two or more metastases, or the patient and family members refuse to undergo more invasive open surgery. And the exclusion criteria: (1) There are absolute contrindiction for surgery, for example, severe cardiopulmonary function, coagulopathy, the basic conditions were poor, and the patients were insupportableness of the operation; (2) Pathological fractures caused by other causes besides tumor destruction, such as osteoporosis; (3) Those with neurological symptoms or intraspinal space occupying a significant need for decompression. The clinical study was authorized by the Ethical Committee of the Four Hospital of Hebei Medical University, and all participants signed an exhaustive informed of the benefits and risks of the procedure.

\section{Pre- and Postprocedural evaluation}

The pain level was evaluated by the VAS ( $0=$ no pain, $10=$ intolerance pain). The BIADL was used to evaluate the patients' quality of life (QoL). Before surgical treatment, patients were detailed examining via X-ray imaging, computed tomography (CT), magnetic resonance imaging (MRI), and bone scintigraphy (ECT). These examinations were used to assess the lesions of the affected vertebrae in all patients and the integrity of the bilateral pedicles of the adjacent upper and lower vertebral segments of the affected vertebrae or to determine the type of lesion (osteogenic, osteolytic, or mixed lesions) and whether epidural spinal cord compression (ESCC) was present (FIGURE 1A, B, C). Before surgery, all patients received lower limbs venous ultrasound examination to evaluate the vascular condition of lower extremity veins. During the operation, the affected vertebral lesion tissue samples were obtained and sent to the pathology 
department of our hospital for examination to evaluate the relationship between the affected vertebral mass tissue and the primary disease. After surgical treatment, the patient's surgical site X-ray was obtained to evaluate the position of pedicle screws and rods, as well as the presence of extravascular PMMA leakage.

\section{Spinal stability and spinal cord injury assessment}

The Spinal Instability Neoplastic Score (SINS) system, developed by the Spinal Oncology Study Group, is used to assess spinal stability[11]. The spinal stability was evaluated by six aspects including spine location, mechanical pain, bone lesion quality, spinal alignment, vertebral body collapse, posterolateral involvement of spinal elements, and obtained corresponding scores (Table 1). The SINS less than 6 is classified as stable spine and does not require surgery; when the score is $6-12$, the spine is relatively unstable and requires observation or surgery. When the score is greater than 12 , the spine is unstable and requires surgical intervention[12]. 
Table 1

Spinal Instability Neoplastic Scoring System

\begin{tabular}{|c|c|}
\hline Category & Score \\
\hline \multicolumn{2}{|l|}{ Location } \\
\hline Junctional (occiput-C2, C7-T2, T11-L1, L5-S1) & 3 \\
\hline Mobile spine (C3-C6, L2-L4) & 2 \\
\hline Semirigid (T3-T10) & 1 \\
\hline Rigid (S2-S5) & 0 \\
\hline \multicolumn{2}{|l|}{ Pain* } \\
\hline Yes & 3 \\
\hline Occasional pain but not mechanical & 1 \\
\hline Pain-free lesion & 0 \\
\hline \multicolumn{2}{|l|}{ Bone lesion } \\
\hline Lytic & 2 \\
\hline Mixed (lytic/blastic) & 1 \\
\hline Blastic & 0 \\
\hline \multicolumn{2}{|l|}{ Radiographic spinal alignment } \\
\hline Subluxation/translation present & 4 \\
\hline De novo deformity (kyphosis/scoliosis) & 2 \\
\hline Normal alignment & 0 \\
\hline \multicolumn{2}{|l|}{ Vertebral body collapse } \\
\hline$>50 \%$ collapse & 3 \\
\hline$<50 \%$ collapse & 2 \\
\hline No collapse with $>50 \%$ body involved & 1 \\
\hline None of the above & 0 \\
\hline \multicolumn{2}{|l|}{ Posterolateral involvement of spinal elements ${ }^{\star \star}$} \\
\hline Bilateral & 3 \\
\hline Unilateral & 1 \\
\hline None of the above & 0 \\
\hline
\end{tabular}


* Mechanical or postural pain is scored in this section. Relief with recumbency supports a structural or mechanical component.

**This section includes pedicles, facets and costovertebral joints.

In addition, patients were evaluated according to the Tomita score (Table 2) and Modified Tokuhashi Scoring System (0-8 points, expected survival $\leq 6$ months, conservative treatment is recommended, 911 points, expected survival $\geq 6$ months, palliative surgery is recommended, $\geq 12$ points, expected survival $\geq 12$ months, resection is recommended) (Table 3)[13].

Table 2

Tomita score prognostic factors and treatment strategies

\begin{tabular}{|llll|}
\hline Score & Primary tumor & Visceral metastases & Bone metastasis \\
\hline 1 & $\begin{array}{l}\text { Slow growth (breast, thyroid, } \\
\text { etc.) }\end{array}$ & None & Solitary \\
\hline 2 & $\begin{array}{l}\text { Moderate growth (kidney, } \\
\text { uterus, etc.) }\end{array}$ & Treatable & Multiple \\
\hline 4 & $\begin{array}{l}\text { Rapid growth (lung, stomach, } \\
\text { etc.) }\end{array}$ & Not treatable & \\
\hline Prognostic score & Treatment goals & Song-term local control & Extensive or marginal resection \\
\hline $2-3$ & Mid-term local control & Marginal or intralesional resection \\
\hline $4-5$ & Short-term local control & Palliative care \\
\hline $8-7$ & Symptomatic treatment & Supportive treatment \\
\hline $8-10$ & & \\
\hline
\end{tabular}


Table 3

Modified Tokuhashi Scoring System

\begin{tabular}{|c|c|}
\hline Prognosis Parameter & Score \\
\hline \multicolumn{2}{|l|}{ General condition (performance status) $^{*}$} \\
\hline Poor (10-40\%) Moderate (50-70\%) & 0 \\
\hline Moderate (50-70\%) & 1 \\
\hline Good $(80-100 \%)$ & 2 \\
\hline \multicolumn{2}{|l|}{ Number of bone metastases outside spine } \\
\hline$\geq 3$ & 0 \\
\hline $1-2$ & 1 \\
\hline 0 & 2 \\
\hline \multicolumn{2}{|l|}{ Number of metastases in spine } \\
\hline$\geq 3$ & 0 \\
\hline 2 & 1 \\
\hline 1 & 2 \\
\hline \multicolumn{2}{|l|}{ Metastases to major organs } \\
\hline Unremovable & 0 \\
\hline Removable & 1 \\
\hline No metastases & 2 \\
\hline \multicolumn{2}{|l|}{ Tumor primary organ } \\
\hline Lung, osteosarcoma, stomach, bladder, esophagus, pancreas & 0 \\
\hline Liver, gallbladder, unidentified & 1 \\
\hline Other & 2 \\
\hline Kidney, uterus & 3 \\
\hline Rectum & 4 \\
\hline Thyroid, breast, prostate, carcinoid tumor & 5 \\
\hline \multicolumn{2}{|l|}{ Spinal cord damage } \\
\hline Complete paraplegia & 0 \\
\hline
\end{tabular}




\begin{tabular}{|ll|}
\hline Prognosis Parameter & Score \\
\hline Incomplete paraplegia & 1 \\
\hline normal & 2 \\
\hline * Performance status according to Karnofsky[14]. & \\
\hline
\end{tabular}

\section{Surgical Procedure}

Spinal surgery was performed on all patients by experienced spinal surgeons. All patients were received PPSF combined with PVP in the prone position after successful general anesthesia and intraoperative antibiotics (Cefmenoxime Hydrochloride for Injection $2.0 \mathrm{~g}, 6.0 \mathrm{~g}$ within 24 hours after surgery) were used to prevent infection. Before surgery, body surface projection of the pedicle of the involved vertebral body and adjacent upper and lower vertebral bodies were determined and marked under the guidance of fluoroscopic devices.

The first stage of the combined procedure is PVP, under the guidance of fluoroscopy device, puncture needles were placed into the pedicles on both sides of the diseased vertebral body. When the puncture needles reached the central site of bone destruction, biopsy forceps were used to remove part of the vertebral mass tissue and sent to the pathology department of our hospital for examination. PMMA was then slowly injected into the affected vertebra under fluoroscopic guidance. During the injection of PMMA, the diffusion of PMMA in the vertebral body should be observed to confirm whether there is leakage of vertebral canal and foraminal cavity, and the patient's vital signs should be closely observed. The total amount of bilateral injection is about $3-6 \mathrm{ml}$, or when the PMMA is close to the posterior edge of the vertebral body or a little PMMA leaks out of the external vertebral space, the injection should be stopped.

The second stage, PPSF, was also guided by a fluoroscopic device, using minimally invasive techniques to place pedicle screws successively into the bilateral pedicles of the adjacent upper and lower segments of the affected vertebra. The puncture position is in the outer upper quadrant of the vertebral pedicle, and the puncture needle Angle should be adjusted at any time under the guidance of the fluoroscopic device to achieve the most satisfactory puncture effect. After the location and Angle of the puncture were determined, 4 or 8 appropriately sized pedicle screws were placed sequentially, and fluoroscopy showed that the pedicle screws were in good position (FIGURE 1D). Two rods of appropriate length are then placed on the pedicle screws through the subcutaneous soft tissue and muscle to ensure normal curvature of the spine. After surgery, all patients underwent x-rays to determine whether the internal fixation was in good position and whether the cement was leaking (FIGURE 1E).

All patients received follow-up therapy such as radiotherapy and chemotherapy to control the further development of the tumor and avoid further compression of the neural structure. The PPSF system and PMMA were provided by the Medical Device Company. 


\section{Clinical Follow-Up}

All patients underwent X-ray reexamination at the end of surgery, seven days, three and six months after operation. Postoperative complications including wound dehiscence, infection, and pedicle screw loosening were recorded. The BIADL and VAS were used to evaluate QoL and pain, respectively. Collect data on all patients on the day of surgery, 7 days, 3months and 6 months after surgery.

\section{Statistical Analysis}

These data were recorded in SPSS 24.0 software (SPSS, inc., Chicago, IL, USA) and analyzed. Measurement data were described by mean and standard deviation $(X \pm S)$, and repeated measures of variance analysis were used to analyze clinical outcomes (VAS score for pain assessment, BIADL scores for improved functionality) at different times. $P$-values less than 0.05 were considered to indicate statistically significant differences.

\section{Results}

We recorded the following information: age, gender, type of primary tumor, diseased vertebral body, volume of PMMA injected and survival time (Table 4). No patient had complications such as PMMA leakage, pulmonary embolism etc. The case series include 8 men and 12 women ranging in age $64.25 \pm$ 10.01 years. The patients' primary malignancies were as follows: 13 cases of lung cancer, 2 case of breast cancer, 3 case of esophageal cancer, 1 case of cervical cancer, 1 case of multiple myeloma.

All patients were evaluated preoperatively: The mean SINS was 9.95 (range, 7-14) for spinal instability assessment according to SINS. According to the Tomita scoring system, the average prognostic score was 6.7 (range, 5-7). According to the Modified Tokuhashi Scoring System, the average prognostic score was 8.6 (range, 6-13). No epidural spinal cord compression was found on MRI images in all patients. 
Table 4

Summary of the Clinical Data of the Patients

\begin{tabular}{|c|c|c|c|c|c|c|}
\hline Patient & gender & Age(yr) & $\begin{array}{l}\text { Primary } \\
\text { Tumor }\end{array}$ & $\begin{array}{l}\text { diseased } \\
\text { vertebral body }\end{array}$ & $\begin{array}{l}\text { dose of PMMA } \\
(\mathrm{mL})\end{array}$ & $\begin{array}{l}\text { Survival } \\
\text { (months) }\end{array}$ \\
\hline 1 & $\mathrm{~F}$ & 53 & breast cancer & T12, L2, L3 & 6 & 11 \\
\hline 2 & $\mathrm{~F}$ & 61 & lung cancer & L2, L3 & 3 & 8 \\
\hline 3 & $\mathrm{~F}$ & 76 & lung cancer & $\mathrm{T} 12$ & 4.5 & 18 \\
\hline $4^{a}$ & $\mathrm{~F}$ & 76 & breast cancer & T11, L3, L4 & 3 & 9 \\
\hline 5 & $M$ & 65 & lung cancer & T11 & 4 & 12 \\
\hline 6 & $\mathrm{~F}$ & 68 & $\begin{array}{l}\text { esophageal } \\
\text { cancer }\end{array}$ & T5 & 1.5 & 25 \\
\hline 7 & M & 69 & lung cancer & L2, L3, L4, L5 & 1.5 & 24 \\
\hline 8 & $\mathrm{~F}$ & 67 & $\begin{array}{l}\text { cervical } \\
\text { cancer }\end{array}$ & T11, L1 & 3 & 6 \\
\hline $9^{b}$ & $\mathrm{~F}$ & 70 & $\begin{array}{l}\text { esophageal } \\
\text { cancer }\end{array}$ & $\mathrm{T} 8$ & 3 & 15 \\
\hline 10 & M & 68 & $\begin{array}{l}\text { esophageal } \\
\text { cancer }\end{array}$ & $\mathrm{T} 10, \mathrm{~T} 11, \mathrm{~T} 12, \mathrm{~L} 1$ & 5 & 7 \\
\hline 11 & $M$ & 61 & lung cancer & T12, L3 & 3 & 20 \\
\hline 12 & $\mathrm{~F}$ & 57 & lung cancer & T9, T11, L3, L4 & 3 & 18 \\
\hline 13 & $\mathrm{~F}$ & 60 & lung cancer & $\mathrm{T} 11, \mathrm{~T} 12, \mathrm{~L} 2, \mathrm{~L} 3$ & 6 & 16 \\
\hline 14 & $\mathrm{~F}$ & 64 & lung cancer & T9 & 1.5 & 14 \\
\hline $15^{c}$ & $M$ & 64 & lung cancer & T11, T12, L3 & 6 & 13 \\
\hline 16 & M & 72 & lung cancer & L4, L5 & 2 & 7 \\
\hline $17^{d}$ & $\mathrm{~F}$ & 67 & lung cancer & T8, T9, L1, L2 & 3 & 21 \\
\hline 18 & $\mathrm{~F}$ & 30 & lung cancer & $\mathrm{T} 10, \mathrm{~T} 12$ & 2 & 9 \\
\hline 19 & M & 64 & $\begin{array}{l}\text { multiple } \\
\text { myeloma }\end{array}$ & $\mathrm{T} 10, \mathrm{~T} 11, \mathrm{~L} 2, \mathrm{~L} 3$ & 2 & 13 \\
\hline 20 & $M$ & 73 & lung cancer & L2 & 3 & 16 \\
\hline \multicolumn{7}{|c|}{$\mathrm{M}=$ male; $\mathrm{F}=$ female } \\
\hline $\begin{array}{l}\text { a-d The } \\
\text { respect }\end{array}$ & atien & d of ur & lying diseas & from surgery, & 15,13 and 21 & hs, \\
\hline
\end{tabular}


20 cases were operated successfully. No patients had syndromes such as PMMA leakage and nerve injury. The median operation time was 54.5 minutes (range, 40-80 minutes), the median blood loss was $35 \mathrm{ml}(20-50 \mathrm{ml})$, and the median dose of PMMA injected was $3 \mathrm{ml}(2-6 \mathrm{ml})$. In all patients, postoperative radiology showed satisfactory internal fixation and good PMMA dispersion.

In this study, 20 patients were followed up for 6-25 months (average time was 14.10 months). Of the 20 patients followed up, 4 patients died of underlying disease at 9, 15, 13 and 21 months postoperatively, and the death was not surgically induced. The surgery was very successful. There were no complications such as infection, pedicle screw loosening or PMMA oozing. There were no deaths due to complications of the operation itself.

The average VAS score for the 20 patients decreased from $7.50 \pm 1.82$ before operation to $3.50 \pm 1.39$ at 7 days after operation and $0.70 \pm 1.03$ at 3 months after operation and $0.30 \pm 0.47$ at 6 months after operation (both $p<0.01$, FIGURE 2). The BIADL score increased from $44.25 \pm 12.49$ preoperatively to $66.00 \pm 11.99$ at 7 days after operation and $85.75 \pm 10.67$ at 3 months after operation and $93.50 \pm 5.88$ at 6 months after operation (both $p<0.01$, FIGURE 3, FIGURE 4). The median overall survival was 13.50 months (FIGURE 5).

\section{Discussion}

In recent years, with the development of comprehensive therapy of tumor, the extension of survival time of tumor patients and the widespread use of MRI, the remedy of spinal metastasis has become a common clinical issue. In the meantime, with the development of the remedy of spinal metastases and the improvement of spinal surgery techniques, surgery has become one of the main methods for the remedy of spinal metastases. This study incorporated 20 patients, all of whom underwent PPSF combined with PVP after detailed preoperative evaluation, all the patients had successful operations, and the VAS scores and BIADL scores of all patients were markedly decreased after surgery. No postoperative complications were observed in any of the surviving patients during postoperative follow-up.

Bone metastases often lead to bone damage, pathological fractures, pain, compressive myelopathy, spinal instability, and other adverse events. $90 \%$ of fractures require surgical treatment $[4,15]$. Skeletal metastasis often occurs in the spine, ribs, pelvis, and proximal femur, but rarely in the upper limb bones and skull. The cervical vertebrae and sacral vertebrae were less involved[16]. The remedy of spinal metastases is complex and challenging, demanding systematic and local treatment with a multidisciplinary or integrated nursing measure, including surgical approaches, targeted treatment and radiation therapy.

Patients with metastatic malignancy often face a poor prognosis, are generally not suitable for surgical removal of the primary neoplasms, and elderly patients are often not suitable for extensive open spinal surgery under general anesthesia to remove the disaffected tissue. These factors greatly limit treatment. The main purpose of treatment for end-stage patients is to ease pain and maintain or restore living quality, and palliative care is often chosen. Surgery, while not the only treatment, can improve spinal 
stability, prevent radiation-induced fractures, effectively ease pain and improve living quality. Now many of the minimally invasive technique is introduced into clinical, these technologies can reduce complications, maintain the integrity of composite longitudinal ligament, reduce the risk of blood loss and infection, accelerate the postoperative recovery, almost all the patients can walk on the first day after surgery.

PVP, a noninvasive procedure in which PMMA is injected into the disease of centrum to ease pain and stabilize the spine, improves the stability of the centrum and avoids the adverse events associated with open surgery[17]. Liu Y used PVP to treat 50 patients with metastatic spine tumors, and all attained good clinical effects[18]. PVP for spinal tumor can better ease pain and improve the living quality, improve the prognosis of patients with metastatic spinal tumor[19]. Nevertheless, PVP can lead to infection, leakage of PMMA, and refracture and collapse of the vertebra after surgery[20,21]. In a study of 30 patients with skeletal metastases, the leakage rate of PMMA was $14.8 \%$ without any clinical sign, which was fortunate, but on the other hand, the rate of PMMA leakage was high. Leak of PMMA into the spinal canal can cause mechanical compression and associated neurological symptoms, or return through the vein can lead to pulmonary embolism, so PPSF should be preferred in patients with ruptured posterior wall and poor spinal stability[22]. Severe osteoporosis is an important factor for vertebral refracture collapse during surgery. The lower the bone density of patients before surgery, the more likely they are to suffer vertebral collapse[23]. If the intraoperative PMMA filling is insufficient, the strength of the vertebral body cannot be recovered well, and the postoperative collapse is easy to occur again.

Compared to vertebroplasty, PPSF can reduce complications and achieve efficient and lasting stability, reduce the pressure above and below the affected vertebra, and partially restore the height of the affected vertebra. Zairi $\mathrm{F}$ et al. treated 44 patients with symptomatic thoracic and lumbar vertebrae metastatic tumor with PPSF, and underwent postoperative radiotherapy within 2 weeks after stabilization. The patients were followed up for 6-12 months and found that the pain was significantly relieved, and no adverse events such as dislocation, hardware damage or loosening occurred during follow-up[24].

Gu $Y$ et al. performed minimally invasive pedicle screw fixation combined with percutaneous vertebroplasty for spinal decompression and partial resection of the tumor in patients with thoracolumbar metastatic tumors. The VAS score was dramatically reduced after operation, and the motor sensory function of most patients back to normal. No changes in spinal curvature or vertebral height were observed during the follow-up, and the spine was considered stable, confirming the effectiveness of the treatment[25].

None of the patients in our study had neurological symptoms, so open spinal decompression was not required. In combination treatment, the PMMA perfusion in PVP has a better supporting function for the affected vertebrae, can reduce the stress of upper and lower pedicle screws, reduce the stress of internal fixation, and effectively avoid the failure of internal fixation. Similarly, pedicle screws can reduce PMMA injection, stabilize adjacent centrum, and reduce PMMA side effects. 


\section{Conclusions}

To sum up, the remedy of metastatic spine tumor is mainly palliative care, so minimally invasive techniques are first adopted to reduce the impact of surgery on critically ill patients, combined with early postoperative radiotherapy to control tumors and prevent further compression of the spinal cord. We believe that PPFS combined with PVP is an effective treatment for thoracic and lumbar metastatic tumors, which can ease the pain of patients and improve their living quality, and is worthy of clinical popularity.

This study has some limitations: 1. Our study design is not a randomized case-control study, but a retrospective study. In addition, we did not set a control group to compare the clinical efficacy. Therefore, our findings cannot be applied to all patients with asymptomatic thoracolumbar metastases.2. Only 20 patients were analyzed and followed up. To better determine the clinical efficacy and prognosis of this operation, the follow-up time and the number of patients should be increased.

\section{Abbreviations}

PPSF: Percutaneous pedicle screw fixation; PVP: Percutaneous vertebroplasty; VAS: Visual analog scale; BIADL: Barthel index of activities of daily living; PMMA: Polymethylmethacrylate; CT: Computed tomography; MRI: Magnetic resonance imaging; ECT: Bone scintigraphy; ESCC: Epidural spinal cord compression; SINS: The Spinal Instability Neoplastic Score; QoL: Quality of life.

\section{Declarations}

\section{Acknowledgements}

Not applicable.

\section{Abbreviations}

PPSF: Percutaneous pedicle screw fixation; PVP: Percutaneous vertebroplasty; VAS: Visual analog scale; BIADL: Barthel index of activities of daily living; PMMA: Polymethylmethacrylate; CT: Computed tomography; MRI: Magnetic resonance imaging; ECT: Bone scintigraphy; ESCC: Epidural spinal cord compression; SINS: The Spinal Instability Neoplastic Score; QoL: Quality of life.

\section{Authors' contributions}

$\mathrm{XM}$ and $\mathrm{HF}$ were responsible for the study conception and design. $\mathrm{XM}$ and $\mathrm{YZ}$ were responsible for the acquisition of data. XM was responsible for the analysis and interpretation of data. XM and JZ were responsible for drafting the manuscript. HW and HF were responsible for the critical revision. All authors read and approved the final manuscript.

\section{Funding}


We do not have any relationship with the manufacturers and have not received any kind of grant from them.

\section{Availability of data and materials}

All data generated or analyzed during this study are included in this published article.

\section{Ethics approval and consent to participate}

Patients were not required to give informed consent to the study because the analysis used anonymous clinical data that were obtained after each patient agreed to treatment by written consent.

\section{Consent for publication}

Not applicable.

\section{Competing interests}

There are no ethical/legal conflicts involved in the article.

\section{References}

1. Fornetti J, Welm AL, Stewart SA. Understanding the Bone in Cancer Metastasis. J Bone Miner Res. 2018;33:2099-113.

2. Piccioli A, Maccauro G, Spinelli MS, Biagini R, Rossi B. Bone metastases of unknown origin: epidemiology and principles of management. J Orthop Traumatol. 2015;16:81-6.

3. Hernandez RK, Wade SW, Reich A, Pirolli M, Liede A, Lyman GH. Incidence of bone metastases in patients with solid tumors: analysis of oncology electronic medical records in the United States. BMC Cancer. 2018;18:44.

4. Kong Y, Ma XW, Zhang QQ, Zhao Y, Feng HL. Gastrointestinal stromal tumor with multisegmental spinal metastases as first presentation: A case report and review of the literature. World $\mathrm{J}$ Clin Cases. 2021;9:1490-8.

5. Xie L, Chen Y, Zhang Y, Yang Z, Zhang Z, Shen L, et al. Status and prospects of percutaneous vertebroplasty combined with ${ }^{12} \mathbb{} \mathrm{I}$ seed implantation for the treatment of spinal metastases. World J Surg Oncol. 2015;13:119.

6. Nassar D, Blanpain C. Cancer Stem Cells: Basic Concepts and Therapeutic Implications. Annu Rev Pathol. 2016;11:47-76.

7. Galgano M, Fridley J, Oyelese A, Telfian A, Kosztowski T, Choi D, et al. Surgical management of spinal metastases. Expert Rev Anticancer Ther. 2018;18:463-72. 
8. Barzilai O, Fisher CG, Bilsky MH. State of the Art Treatment of Spinal Metastatic Disease. Neurosurgery. 2018;82:757-69.

9. Yang Z, Yang Y, Zhang Y, Zhang Z, Chen Y, Shen Y, et al. Minimal access versus open spinal surgery in treating painful spine metastasis: a systematic review. World J Surg Oncol. 2015;13:68.

10. Cazzato RL, Buy X, Grasso RF, Luppi G, Faiella E, Quattrocchi CC, et al. Interventional Radiologist's perspective on the management of bone metastatic disease. Eur J Surg Oncol. 2015;41:967-74.

11. Fisher CG, DiPaola CP, Ryken TC, Bilsky MH, Shaffrey $\mathrm{Cl}$, Berven SH, et al. A novel classification system for spinal instability in neoplastic disease: an evidence-based approach and expert consensus from the Spine Oncology Study Group. Spine (Phila Pa 1976). 2010;35:E1221-9.

12. Murtaza H, Sullivan CW. Classifications in Brief: The Spinal Instability Neoplastic Score. Clin Orthop Relat Res. 2019;477:2798-803.

13. Ulmar B, Huch K, Naumann U, Catalkaya S, Cakir B, Gerstner S, et al. Evaluation of the Tokuhashi prognosis score and its modifications in 217 patients with vertebral metastases. Eur $\mathrm{J}$ Surg Oncol. 2007;33:914-9.

14. Shamseddeen H, Pike F, Ghabril M, Patidar KR, Desai AP, Nephew L, et al. Karnofsky performance status predicts outcomes in candidates for simultaneous liver-kidney transplant. Clin Transplant. 2021;35:e14190.

15. Duo J, Han X, Zhang L, Wang G, Ma Y, Yang Y. Comparison of FDG PET/CT and gadoliniumenhanced MRI for the detection of bone metastases in patients with cancer: a meta-analysis. Clin Nucl Med. 2013;38:343-8.

16. Liu Y, Sheng J, Dong Z, Xu Y, Huang Q, Pan D, et al. The diagnostic performance of 18F-fluoride PET/CT in bone metastases detection: a meta-analysis. Clin Radiol. 2019;74:196-206.

17. Orgera G, Krokidis M, Rebonato A, Tipaldi MA, Mascagni L, Rossi M. Thyroid skeletal metastasis: pain management with verteblation. BMJ Support Palliat Care. 2019;9:e2.

18. Liu Y, Wang Y, Zhao L, Song R, Tan H, Wang L. Effectiveness and safety of percutaneous vertebroplasty in the treatment of spinal metastatic tumor. Pak J Med Sci. 2017;33:675-9.

19. Qi L, Li C, Wang N, Lian H, Lian M, He B, et al. Efficacy of percutaneous vertebroplasty treatment of spinal tumors: A meta-analysis. Medicine (Baltimore). 2018;97:e9575.

20. Park JW, Park SM, Lee HJ, Lee CK, Chang BS, Kim H. Infection following percutaneous vertebral augmentation with polymethylmethacrylate. Arch Osteoporos. 2018;13:47. 
21. Bae JW, Gwak HS, Kim S, Joo J, Shin SH, Yoo H, et al. Percutaneous vertebroplasty for patients with metastatic compression fractures of the thoracolumbar spine: clinical and radiological factors affecting functional outcomes. Spine J. 2016;16:355-64.

22. Mansour A, Abdel-Razeq N, Abuali H, Makoseh M, Shaikh-Salem N, Abushalha K, et al. Cement pulmonary embolism as a complication of percutaneous vertebroplasty in cancer patients. Cancer Imaging. 2018;18:5.

23. Kim HS, Heo DH. Percutaneous Pedicle Screw Fixation with Polymethylmethacrylate Augmentation for the Treatment of Thoracolumbar Intravertebral Pseudoarthrosis Associated with Kummell's Osteonecrosis. Biomed Res Int. 2016;2016:3878063.

24. Zairi F, Vielliard MH, Bouras A, Karnoub MA, Marinho P, Assaker R. Long-segment percutaneous screw fixation for thoraco-lumbar spine metastases: a single center's experience. J Neurosurg Sci. 2017;61:365-70.

25. Gu Y, Dong J, Jiang X, Wang Y. Minimally Invasive Pedicle Screws Fixation and Percutaneous Vertebroplasty for the Surgical Treatment of Thoracic Metastatic Tumors With Neurologic Compression. Spine (Phila Pa 1976). 2016;41 Suppl 19:B14-14B22.

\section{Figures}



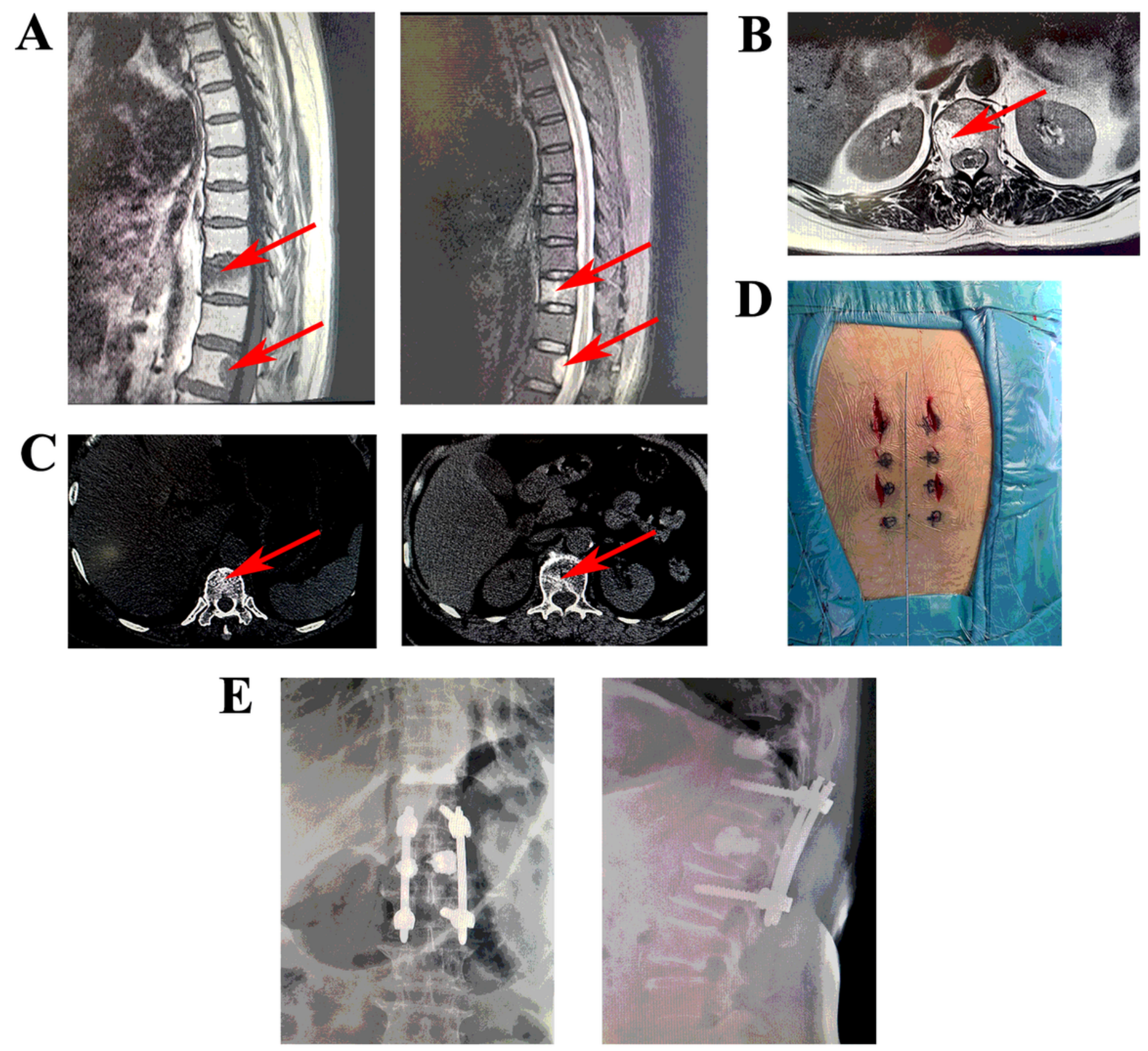

\section{Figure 1}

A, Sagittal MRI showed significant vertebral mass in the T11 and L1, which was due to cancer metastasis in a 67-year-old woman. B, Axial MRI showed significant vertebral mass in the L1. C, Axial CT showed lesions in the T11 and L1 vertebral bodies. D, The picture shows the size of the wound after the operation. $\mathrm{E}$, Frontal and lateral view of postoperative radiographs (Case 8). 
A

VAS score, Before operation vs post-op(7D, 3M, 6M)

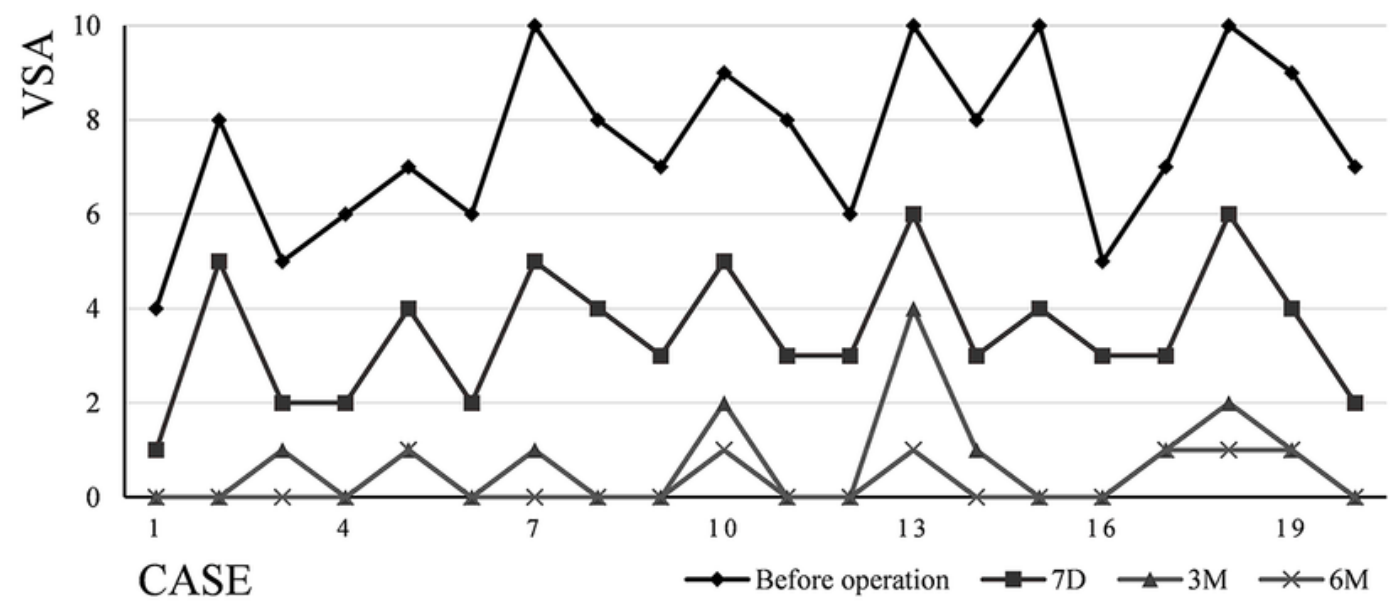

B

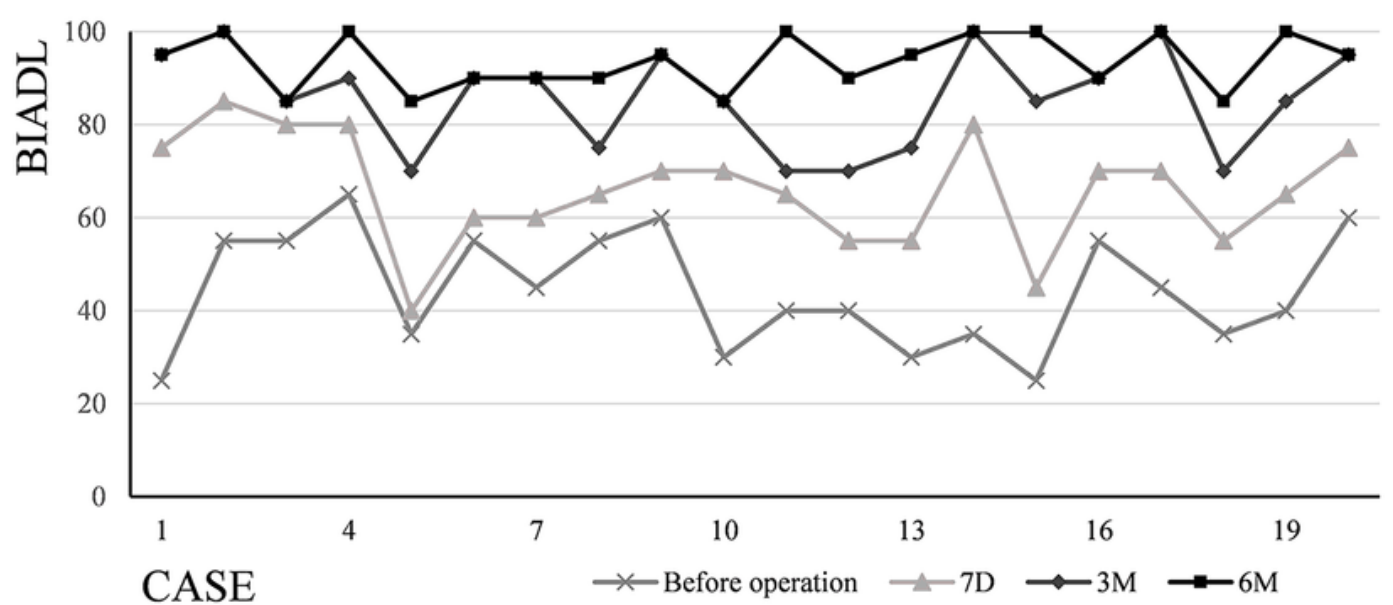

C

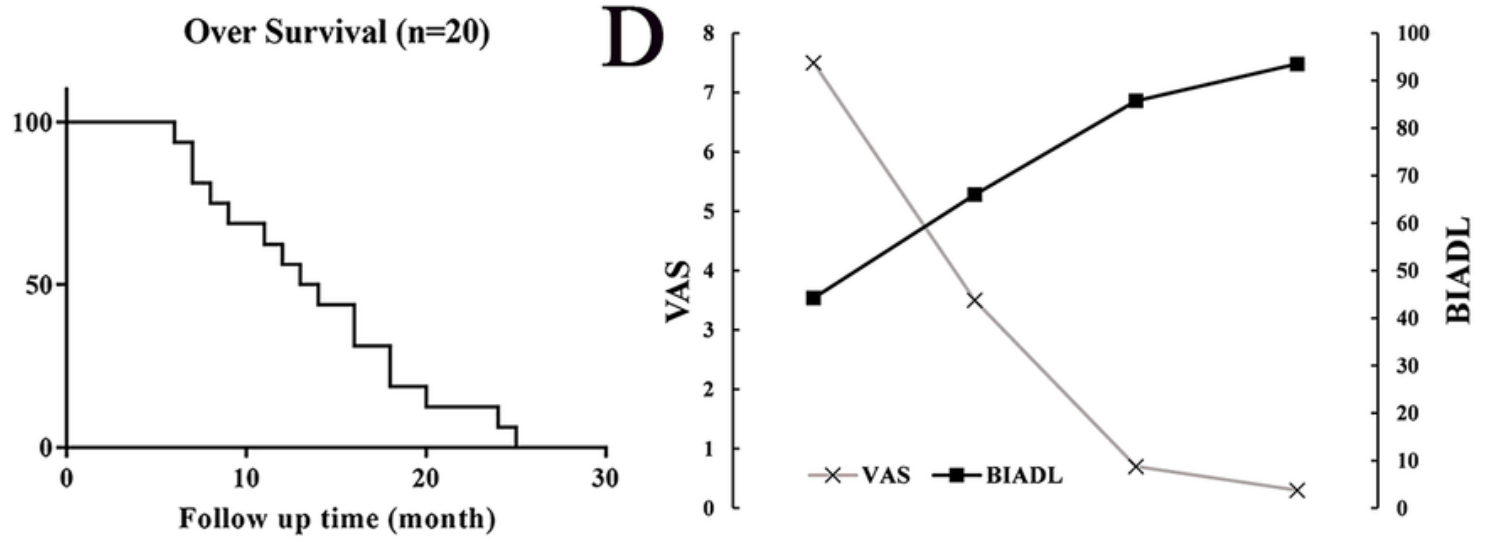

Figure 2

A, VAS scores for pain. B, BIADL scores for patient's QoL. C, Changes in VAS and BIADL scores after PPSF combined with PVP. D, Overall survival curve. 